\title{
Intrusive thoughts, sensation seeking, and drug use in college students
}

\author{
ANNIE M. HINES and GERALDINE A. SHAW \\ Georgetown College, Georgetown, Kentucky
}

\begin{abstract}
The relationships between drug use, task-unrelated thoughts (TUTs), self-reported sensation seeking, retrospective self-reported personality characteristics, laterality, eye dominance, and allergies in college students who were diagnosed in childhood as having attention deficit/hyperactivity disorder (ADHD) was investigated. Three groups (high- and low-activity and ADHD subjects) reported both spontaneous and deliberate TUTs during a vigilance task. Intrusive thoughts were found to be predictive of drug use/attitudes, but, to a greater extent, sensation seeking accounted for most drug-related behavior. Left-eye dominance was related to increased childhood hyperactive behaviors and to spontaneous TUTs. Of the three groups, subjects diagnosed as having ADHD had more spontaneous TUTs. These results are consistent with biological models.
\end{abstract}

A recent research report has demonstrated a relationship between attention deficit/hyperactivity disorder (ADHD) and spontaneous thoughts (Shaw \& Giambra, 1993). Another recent study has provided evidence that adult ADHD individuals are prone to drug and alcohol use (Mannuzza et al., 1991). A plausible implication of these two studies is that ADHD persons wish to stop the discomfort of unbidden thoughts. This suggested relationship deserves investigation.

The main findings of Shaw and Giambra (1993) were that subjects diagnosed with ADHD as children exhibited the greatest frequency of spontaneous thoughts, left-eye dominance, and sensation seeking. Shaw and Giambra (1993) stated that

\begin{abstract}
our ADHD individuals, hypoaroused and seeking optimum levels of sensation (or perhaps increasingly aroused because boredom is extremely stressful to them) have higher levels of nonconscious processing (from fleeting sensory input and/or previous thought) and subsequent semantic activation. The results of these processes emerge rapidly into consciousness as spontaneous thoughts. In ADHD individuals, the uncontrolled spontaneous thoughts may be disrupting attention such that they cannot concentrate on the task at hand. In other words, when ADHD individuals are bored their semantic activation processes seem more random and may cause mental discomfort to these individuals resulting in poor coordination of attentional and inhibitional processes. (p. 28)
\end{abstract}

The two general theories used by Shaw and Giambra (1993) to explain intrusive thoughts in ADHD persons involved arousal levels and impulsivity. Klove (1989) cites a great deal of evidence supporting the hypoarousal hypothesis, which states that ADHD children seem to need stimulation as a result of underarousal in the reticular activating system and cortex. Zuckerman $(1979,1983)$

\footnotetext{
We are grateful to L. M. Giambra and E. Rosenberg, of the National Institute on Aging, for allowing us to use the computer task, and to the students who served as our subjects. Requests for reprints should be sent to G. A. Shaw, Department of Psychology, Georgetown College, KY 40324.
}

views sensation seeking as a stable, biologically based personality trait defined as "the need for varied, novel, and complex sensations and experiences and the willingness to take physical and social risks for the sake of such experiences" (Zuckerman, 1979, p. 37). Many studies linking high sensation seeking with ADHD children suggest an attempt by ADHD children to increase their arousal levels through external stimulation.

Impulsivity is at the center of a second theory in which ADHD persons exhibit poor inhibition and control of behavior. ADHD children are impulsive, and Rutter (1989) suggests that they have difficulty in inhibiting their actions. Logan (1989) concluded that some automatic processes, which come unbidden and unwanted, can be cognitively controlled by most individuals. Spontaneous, unbidden thought may occur as a result of a breakdown of inhibitory control of thoughts, resulting in awareness of them, and thus should be more frequent in ADHD individuals.

Douglas (1983) suggests that most ADHD children function outside their optimal range of arousal most of the time. It is possible that intrusive thoughts are uncontrollable and uncomfortable and that drugs are used to alter this situation.

To examine the relationship between thought intrusions and drug use/attitudes, we used available samples of college students who had been diagnosed as having ADHD in childhood, as well as high- and low-activity subjects. The variables considered important in this examination were sensation seeking, laterality of function, self-reported activity level, drug use/attitudes, and the presence of spontaneous thoughts. Shaw and Giambra's (1993) vigilance task, in which subjects reported the occurence of spontaneous task-unrelated thoughts (TUTs) and deliberate thoughts, was employed. We hypothesized a relationship between spontaneous TUTs, sensation seeking, and drug use/attitudes. We also expected to find higher levels of hyperactivity, sensation seeking, left-sidedness, and intrusive thoughts in our ADHD subjects than in the other groups. 


\section{METHOD}

\section{Survey Subjects}

One hundred thirty-two Georgetown College undergraduates were screened for personal characteristics associated with ADHD (retrospectively at the age of 10-12 years, and presently). During class sessions, students reported these characteristics by completing a two-part questionnaire: the Characteristics Rating-Child (CR-C), and the Characteristics Rating-Adult (CR-A). Drug attitudes and use were measured with the Drug Scale devised for this study (unpublished; adapted from Palmgreen et al., 1991).

The CR-C and CR-A measures each comprise 15 characteristics typical of hyperactive individuals (drawn from Hopkins, Perlman, Hechtman, \& Weiss, 1979; Weiss, 1983; and Weiss \& Hechtman, 1986). Students rated themselves on a 7-point Likert scale-first, on each characteristic retrospectively for childhood at 10-12 years (CR-C), and second, on their present characteristics (CR-A). Seven items dealt with positive characteristics (concentration, self-esteem, social maturity, finishing of tasks, setting short-term goals, happiness, motivation) and eight items dealt with negative characteristics (impulsiveness, recklessness, gaining attention, touching and examining things, level of activity, school problems, distractibility, suffering criticism).

The Drug Scale (DS) consists of four subscales: (1) Drug Attitudes for Myself, (2) Drug Attitudes for My Friends, (3) First Use of Drugs, and (4) Last Month Usage. The first two subscales consist of five statements concerning attitudes toward drugs, rated on a 7-point Likert scale. The third subscale involves nine drug and alcohol categories (tobacco, beer or wine, hard liquor, marijuana, LSD, amphetamines, barbiturates, tranquilizers, and cocaine). The students were asked to circle the age (never, $<11$ to $18+$ ) at which each substance had been first used. The fourth subscale involves the same nine drug and alcohol categories. The students were asked how often they had used each substance in the past 30 days (not at all, less than once a week, once or twice a week, three to four times a week, almost every day). The distribution of CR-C, CR-A, and DS scores for the 132 undergraduates is presented in Table 1.

Significant correlations were obtained for CR-C and DS-me ( $r=.21$, $p<.009)$, for CR-C and DS-first use $(r=.24, p<.006)$, and for several drugs. In addition, the correlation between distractibility, 1 of the 15 characteristics on the CR-A, and last month use was highly significant $(r=.22, p<.009)$. This was taken as evidence that the college contained a population suitable for a study in which the relationship between spontaneous thoughts and drug attitudes and use was examined.

\section{Experimental Subjects}

A second survey, using the characteristics scale, was administered to 134 undergraduates. This questionnaire also solicited information on ADHD status. Of the undergraduates who had been diagnosed by a school psȳchologist or physician as hyperactive during childhood, 5 male and 5 female Georgetown College students were selected to form the ADHD group. The diagnostic label $A D H D$, which has now replaced the former term attention deficit disorder (ADD) that was in use when our subjects were diagnosed, will be used in this paper. Two additional groups (high and low) were formed by enlisting 5 subjects each from the upper and lower quartiles of the CR-C score ranges (see Shaw \& Giambra, in press) for males and for females: 5 high-males (CR-C > 67) and 5 high-females (CR-C $>62$ ) for the high group; and 5 low-males (CR$\mathrm{C}<56$ ) and 5 low-females (CR-C $<47$ ) for the low group. All sub-

Table 1

Scores at Five Percentiles and Standard Deviations, for the Two Scales of the Characteristics Rating (CR-C, CR-A) and the Drug Scale (DS)

\begin{tabular}{lrrrrrr}
\hline & \multicolumn{5}{c}{ Percentile } \\
\cline { 2 - 6 } \multicolumn{1}{c}{ Variable } & 100 & 75 & 50 & 25 & 1 & $S D$ \\
\hline CR-C & 80 & 55 & 58 & 53 & 36 & 9.09 \\
CR-A & 71 & 54 & 48 & 43 & 30 & 7.92 \\
DS-me & 28 & 8 & 5 & 5 & 5 & 5.21 \\
DS-friend & 25 & 13 & 5 & 5 & 5 & 6.07 \\
DS-first use & 65 & 14 & 8 & 3 & 0 & 9.60 \\
DS-monthly use & 13 & 2 & 0 & 0 & 0 & 2.26 \\
\hline
\end{tabular}

jects participated either in partial fulfillment of a course requirement or as unpaid volunteers.

\section{Instruments and Tasks}

1. The Sensation Seeking Scale-Form V (Zuckerman, 1979): measures sensation seeking by self-report; maximum score, 40 .

2. The Allergy Checklist (Shaw, 1992): lists typical allergies in infancy and childhood and seeks information about the allergies of family members.

3. The Laterality Questionnaire (Shaw, 1992): seeks information about laterality of function for 10 specific tasks and information about the handedness of family members.

4. The Conners Abbreviated Rating Scale (Conners, 1973): a commonly used scale for determining hyperactivity in children, usually completed by a parent or teacher. We asked subjects to retrospectively judge themselves (at age 10-12 years). The highest possible score was 30 .

5. The Drug Scale, previously described, was also administered.

6. The Characteristics Scale-Child and Adult (Shaw \& Giambra, 1993) previously described, was also administered.

7. The Vigilance Task and Task-Unrelated-Thought Recording (TUT; Shaw \& Giambra, 1993): measures spontaneous and deliberate TUTs in a 20-min test controlled by an IBM microcomputer (Model 8330$002)$. Subjects were required to press the space bar when a small " $x$ " appeared on the screen and not to press any key when a large " $X$ " appeared on the screen. The subjects were also asked to differentiate between those of their thoughts that were related to the task and those that were unrelated to the task (TUTs). The TUTs were further differentiated into deliberate and spontaneous TUTs, which were recorded by keypress at random intervals. A detailed description of this task can be found in Shaw and Giambra (1993).

\section{Procedure}

All subjects were tested individually in a psychology laboratory while seated at a desk. The subjects first completed the Allergy Checklist, the Sensation Seeking Scale, the Laterality Questionnaire, the Conners Abbreviated Rating Scale, and the Drug Scale. This took 25-30 min. Then, subjects were directed to the chair in front of the monitor and asked to make themselves as comfortable as they could. While the vigilance task instructions were given verbally, the subject read along. The experimenter stayed with the subject during a 2-min practice session, answering questions as needed and ensuring that the subject understood what was to be done. The subject was then left alone for a 5-min practice session, after which the experimenter asked whether clarification was needed. Finally, the subject was left alone for the 20-min experimental session.

At the end of the session, subjects were given a questionnaire asking their estimates of the number of times the TUT buttons were pressed for spontaneously and deliberately arising thoughts, and for any difficulties encountered.

\section{RESULTS}

\section{Descriptive Analysis}

The CR-C scale was used to select subjects for the high and low groups. The three groups were labeled high, low, and $A D H D$. Table 2 shows that the ADHD mean was 63.9 , which is slightly lower than that for the high group $(M=68.8)$ and much greater than that for the low group $(M=44.9)$.

\section{Analyses of Variance}

One-way analyses of variance (ANOVAs) across the three groups were performed on the Sensation-Seeking Scale (SSS), Conners, CR-A, spontaneous TUTs, deliberate TUTs, and DS (See Table 2). Groups had a significant effect on spontaneous TUTs $\left[F(2,27)=4.80, M S_{\mathrm{e}}=\right.$ $70.9, p<.02]$. The correlations of spontaneous TUTs with the DS $(r=.35, p<.05)$ and Conners $(r=.55$, $p<.002)$ measures were significant. Groups failed to 
have a significant effect on deliberate TUTs. These results showed that spontaneous thoughts were significantly higher for the ADHD group. However, there were no significant differences for deliberate thoughts.

When the SSS was used as the dependent variable, a significant result was achieved $\left[F(2,27)=4.04, M S_{e}=\right.$ $32.3, p<.03]$. Sensation seeking was approximately equal for the ADHD and high groups and much higher than in the low group. In addition, correlations of the SSS with the Conners $(r=.51, p<.004)$ and CR-A $(r=.49$, $p<.006)$ measures were significant. Thus, there seem to be commonalities among these three activity measures.

The effect of groups on the Conners scale was highly significant $\left[F(2,27)=32.35, M S_{\mathrm{e}}=13.3, p<.0001\right]$. The mean of the ADHD group was highest (17.8), that of the high group was second highest (9.9), and that of the low group was lowest (4.8). This distribution was to be expected; it indicates that the Conners scale measures different aspects of activity than do the SSS and Characteristics scales. The correlations of the Conners scale with the child allergies $(r=.49, p<.007), \mathrm{CR}-\mathrm{A}(r=.52$, $p<.003)$, and DS $(r=.41, p<.03)$ measures were significant. It has been suggested that the discomfort of allergies might be responsible for drug use, but no significant correlations among allergies, DS, and spontaneous TUTs emerged.

When the CR-A was employed as the dependent variable, a significant result was obtained $\left[F(2,27)=11.47, M S_{\mathrm{e}}=\right.$ $100.0, p<.0002]$. The mean CR-A values for the ADHD and high groups were approximately equal (57.5 and 57.4) but much lower for the low group (38.9). This seems to indicate that the CR-A did not distinguish between our two high-activity groups as well as the Conners does.

The effect of groups on the DS was highly significant $\left[F(2,27)=6.22, M S_{\mathrm{e}}=253.5, p<.006\right]$. However, in this case, the high group showed much higher scores than did the ADHD group (43.0 and 37.1). This was also evident in the extremely significant correlation between the SSS and DS $(r=.69, p<.0001)$. This suggests that while sensation seeking may be important in high-activity subjects, it does not entirely account for drug use in ADHD individuals.

\section{Regression Analyses}

The data were subjected to regression analysis to determine whether spontaneous TUTs would predict drug use and attitudes. The analysis tested the hypothesized model with DS as the independent variable and with the predicting factors ordered in the following manner: spontaneous TUTs, deliberate TUTs, SSS, Conners, CR-A, CR-C, and laterality. The total model was highly significant $\left[F(7,22)=4.48, M S_{\mathrm{e}}=187.3, p<.003\right]$. The factors that significantly predicted drug use were spontaneous TUTs $[F=6.72, p<.02]$ and SSS $[F=19.1, p<$ .0002 ). This evidence supports the hypothesis that the variable of spontaneous thoughts will predict drug use and attitudes. Although it appears that the variable of sensation seeking is very stong in accounting for drug use, it also appears that for our subgroup of sensation seekers, the ADHD subjects, spontaneous thoughts are also important.

\section{Discriminant Analysis}

The discriminant analysis also proved to be of high significance (see Table 3 ). The variables that proved to be significant in sorting subjects into appropriate groups were, in order of significance: Conners, drug use, spontaneous thoughts, child allergies, eyedness, and sensation seeking. When taken from the perspective of discriminating between groups, sensation seeking takes on a much less important role than other variables do. A factor directly related to ADHD, the Conners scale, is the most highly significant sorting factor. The next two most important factors are drug use and spontaneous TUTs. In other words, the sensation-seeking factor, even though strongly linked with drug use, is not as significant in discriminating among groups as are ADHD-related factors.

On the basis of the single significant function in Table 3 , membership in a specific group was predicted for all members of the low group, $80 \%$ of the high group, and $90 \%$ of the ADHD group. This seems to be an ac-

Table 2

Means and Standard Deviations on All Measures for the Attention Deficit/Hyperactivity Disorder (ADHD), High, and Low Groups and ANOVAs with the Groups as Independent Variables and with Characteristics Rating (CR-A, adult; CR-C, child), Conners Spontaneous Task-Unrelated Thoughts (TUTs), Deliberate TUTs, Drug Scale, and Sensation-Seeking Scale as Dependent Variables in Separate Analyses

\begin{tabular}{|c|c|c|c|c|c|c|c|c|}
\hline \multirow[b]{3}{*}{ Measure } & \multicolumn{6}{|c|}{ CR-Child Level Groups } & \multirow[b]{3}{*}{$F$} & \multirow[b]{3}{*}{$p<$} \\
\hline & \multicolumn{2}{|c|}{ ADHD } & \multicolumn{2}{|c|}{ High } & \multicolumn{2}{|c|}{ Low } & & \\
\hline & $M$ & $S D$ & $M$ & $S D$ & $M$ & $\overline{S D}$ & & \\
\hline CR-C & 63.9 & 5.7 & 68.8 & 5.9 & 44.9 & 7.6 & & \\
\hline CR-A & 57.5 & 8.5 & 57.4 & 14.2 & 38.9 & 5.2 & 11.47 & .0002 \\
\hline Connors & 17.8 & 5.4 & 9.9 & 2.9 & 4.8 & 1.4 & 32.35 & .0001 \\
\hline TUT-spontaneous & 23.3 & 9.6 & 18.6 & 6.0 & 11.7 & 9.2 & 4.80 & .02 \\
\hline TUT-deliberate & 15.6 & 11.0 & 17.7 & 10.3 & 13.1 & 6.6 & .56 & n.s. \\
\hline Drug Use Scale & 37.1 & 18.1 & 43.0 & 19.4 & 18.9 & 7.4 & 6.22 & .006 \\
\hline Sensation seeking & 20.7 & 6.1 & 19.7 & 7.0 & 14.0 & 3.4 & 4.04 & .03 \\
\hline Laterality & 5.0 & 4.6 & 5.8 & 3.2 & 5.9 & 4.5 & & \\
\hline Allergies & 3.4 & 2.6 & 3.5 & 3.5 & 0.6 & 0.8 & & \\
\hline Age & 20.6 & 2.8 & 19.5 & 0.8 & 19.7 & 2.6 & & \\
\hline
\end{tabular}


Table 3

Discriminant Analysis Statistics

\begin{tabular}{lccr}
\hline \multicolumn{1}{c}{ Variable } & Wilks's & $F(1,28)$ & \multicolumn{1}{c}{ Univariate } \\
\hline Conners & 0.29 & 32.4 & .000 \\
Drug Scale & 0.68 & 6.2 & .006 \\
Spontaneous task-unrelated thoughts & 0.74 & 4.8 & .02 \\
Eyedness & .076 & 4.2 & .03 \\
Child allergies & 0.77 & 4.1 & .03 \\
Sensation seeking & 0.77 & 4.0 & .03 \\
Deliberate task-unrelated thoughts & 0.96 & 0.6 & .56 \\
Laterality & 0.99 & 0.1 & .87 \\
\hline
\end{tabular}

Note-Canonical discriminant functions are as follows: functions, 1 ; eigenvalue, $3.47 ; \%$ variance, 89.79 ; cumulative $\%, 89.79$; canonical correction, .88; after function, 0 ; Wilks's $\lambda, .16 ; \chi^{2}(16)=43.0, \mathrm{p}<$ .0003 .

ceptable level of subjects correctly classified by the six variables in combination. However, the misclassification of 3 subjects may have caused a confounding of the measurement in some unknown way.

The numbers of left-eyed individuals in the groups were as follows: ADHD, 5; high, 2; low, 0. Left-eye dominance correlated with CR-A $(r=.51, p<.004)$ and with spontaneous TUTs $(r=.41, p<.02)$. Thus, left-eye dominance, as in Shaw's (1992) and Shaw and Giambra's (1993) studies, was more evident in the ADHD group. It is not clear why stronger left-sidedness should correspond to decreased ability to keep one's mind from wandering.

\section{DISCUSSION}

Children with ADHD have been characterized as having an underaroused nervous system, and their hyperactivity has been hypothesized as stemming from a need to achieve a more appropriate level of arousal. The expected interconnected relationships among the CR-C, the Conners scale, and sensation seeking did emerge, and they lend support to the arousal level theory (Klove, 1989). However, although sensation seeking accounts for drug-related behavior in high-activity subjects more than intrusive thoughts do, this study and previous work indicate that ADHD subjects experience more of such internal disruptions, which may account for some of their behavior. The result that ADHD subjects have the highest numbers of intrusive TUTs supports Logan's (1989) theory that hyperactives have poor inhibition and cognitive control processes.

The present evidence suggests that drug behaviors are related to intrusive thoughts and supports the main hypothesis of this experiment. It is interesting that subjects also gave an anecdotal connection between drug use and poor control: drugs are taken in order to escape uncomfortable thoughts. However, additional work is needed to determine whether the effect is robust. It must also be stated that these results may not apply to ADHD people generally, because the subjects were functioning successfully at the college level.

The resulting relationship between drug behaviors and spontaneous TUTs in the ADHD subjects is consistent with biological models. According to Zuckerman (1991), low levels of monoamine oxidase (MAO) have been found in alcoholics, chronic marijuana users, and boys with ADHD. He also emphasizes that MAO levels are negatively related to behavioral performance measures of impulsivity and attentiveness. Although these studies do not link MAO specifically to intrusive thoughts, there is evidence that inhibition of MAO may prolong the actions of neurotransmitters and produce mania (Bloom \& Lazerson, 1988). It is possible that in situations that are enormously frustating to ADHD sub- jects, such as the vigilance task, a manic-like state exists to the point at which thought intrusions occur.

The robust relationship between sensation seeking and drug-related behaviors was also found in the present work. Cox (1985) found that sensation seeking is not influential in the choice of psychoactive drugs, although high sensation seekers do resort to more frequent drug-related behaviors. A more general biological explanation is given by Bardo and Mueller (1991), who suggest that sensation seeking has been reformulated from an optimal arousal model to a brain reward model. They also believe that MAO plays an important role in both sensation seeking and drug use.

\section{REFERENCES}

BARDO, M., \& Mueller, C. (1991). Sensation-seeking and drug abuse prevention from a biological perspective. In L. Donohew, H. Sypher, \& W. Bukoski (Eds.), Persuasive communication and drug abuse prevention (pp. 195-207). Hillsdale, NJ: Erlbaum.

Bloom, A., \& LAzerson, A. (1988). Mind, brain and behavior. New York: W. H. Freeman.

CoNNERs, C. K. (1973). Rating scales for use in drug studies with children. Psychopharmacology Bulletin, 9, 24-84.

Cox, W. M. (1985). Personal correlates of substance abuse. In M. Galizio \& S. A. Maisto (Eds.), Determinants of substance abuse (pp. 209246). New York: Plenum.

Douglas, V. I. (1983). Attentional and cognitive problems. In M. Rutter (Ed.), Developmental Neuropsychiatry (pp. 281-329). New York: Guilford.

Hopkins, J., Perlman, T., Hectman, L., \& Weiss, G. (1979). Cognitive style in adults originally diagnosed as hyperactives. Journal of Child Psychology \& Child Psychiatry, 20, 209-216.

KLOVE, H. (1989). The hypoarousal hypothesis: What is the evidence? In T. Sagvolden \& T. Archer (Eds.), Attention deficit disorder (pp. 131-136). Hillsdale, NJ: Erlbaum.

LoGAN, G. D. (1989). Automaticity and cognitive control. In J. S. Uleman \& J. Bargh (Eds.), Unintended thought (pp. 52-74). New York: Guilford.

Mannuzza, S., Klein, R., Bonagura, N., Molloy, P., GiamPINO, T., \& ADDALLI, K. (1991). Hyperactive boys almost grown up. Archives of General Psychiatry, 48, 77-83.

Palmgreen, P., Lorch, E. P., Donohew, C., Helm, D. M., Baer, S. A., \& Dsilva, M. (1991, May). Program, context, sensation seeking, and attention to televised anti-drug public service announcements. Paper presented to the Communications Division of the International Communications Association Annual Conference, Chicago.

RUTTER, M. (1989). ADD/hyperkinetic Syndrome: Conceptual and research issues regarding diagnosis and classification. In T. Sagvolden \& T. Archer (Eds.), Attention deficit disorder (pp. 1-24). Hillsdale, NJ: Erlbaum.

SHAw, G. A. (1992). Hyperactivity and creativity: The tacit dimension. Bulletin of the Psychonomic Society, 30, 157-160.

Shaw, G. A., \& Giambra, L. (1993). Task-unrelated-thoughts in college students diagnosed as hyperactive in childhood. Developmental Neuropsychology, 9, 17-30.

WeISS, G. (1983). Long-term outcome: Findings, concepts and practical implications. In M. Rutter (Ed.), Developmental neuropsychiatry (pp. 422-436). New York: Guilford.

WEISS, G., \& HechtmaN, L. (1986). Hyperactive children grown up. New York: Guilford.

Zuckerman, M. (1979). Sensation seeking: Beyond the optimal level of arousal. Hillsdale, NJ: Erlbaum.

ZuCKERMAN, M. (1983). Biological bases of sensation seeking, impulsivity, and anxiety. Hillsdale, NJ: Erlbaum.

ZuCKerman, M. (1991). The psychobiology of personality. New York: Cambridge University Press.

(Manuscript received June 11, 1993.) 